\title{
Angiotensin converting enzyme in bronchoalveolar lavage fluid in pulmonary sarcoidosis
}

\author{
M PERRIN-FAYOLLE, Y PACHECO, R HARF, B MONTAGNON, N BIOT \\ From the Service de Pneumologie, Hôpital Jules Courmont, Sainte Eugénie, Lyon, France
}

ABSTRACT Alveolar angiotensin converting enzyme (ACE) and serum ACE were measured simultaneously in 16 patients with histologically confirmed sarcoidosis and in 16 control subjects. Although alveolar ACE was abnormally elevated in all 16 cases of active sarcoidosis, serum ACE was not. No correlations were found between radiographic staging of pulmonary sarcoidosis and the levels of these enzymes. There was a clear correlation, however, between the levels of alveolar ACE and counts made on bronchoalveolar lavage fluid. This correlation was closer than that existing between serum ACE and bronchoalveolar lavaged lymphocytes. It is suggested that alveolar ACE is an additional biological marker of pulmonary sarcoidosis which is possibly more sensitive than serum ACE.

A number of papers ${ }^{1-6}$ have described serum ACE levels as a valuable biological marker in the diagnosis and management of sarcoidosis. The studies of bronchoalveolar lavage fluid 78 are fewer and appear to be contradictory. Thus Gupta et $a l^{7}$ found no alteration in alveolar ACE levels during active sarcoidosis, whereas Lanzillo and Fanburg ${ }^{8}$ showed a significant increase in the level of this enzyme in bronchoalveolar washings. In addition to changes in enzyme levels important alterations in the numbers of mononuclear cells have been demonstrated in active sarcoidosis. 5910

In view of these results it is of particular interest that in the course of sarcoidosis immune responses vary considerably in different parts of the body, producing depressed sensitivity in the blood, while lymphocytes proliferate in alveolar tissue. Furthermore, the extent of lymphocyte proliferation in alveolar tissue seems to indicate the degree of activity of the disease and is presently the subject of a number of studies concerning $\mathrm{T}$ lymphocyte subpopulations. Moreover, there is a phenomenon of macrophage activation in alveolar tissue. Gee $e t a l^{5}$ suggest that macrophages are an important source of ACE activity and also that the enhancement of ACE activity in sarcoid macrophages is evidence of "activation" of the tissue mononuclear phagocyte in sarcoidosis.

Address for reprint requests: Dr Y Pacheco, Service de Pneumologie, Hôpital Jules Courmont, Sainte Eugénie, Avenue G Clémenceau, 69230 Saint Genis Laval, Lyon, France.

\section{Methods}

The groups studied comprised 16 patients with pulmonary sarcoidosis and 16 control subjects free of respiratory disease. The sarcoidosis group included nine women and seven men aged between 27 and 57 years. Only one of these patients was a smoker. Sarcoidosis had been proved histologically by biopsy (lymph node, bronchus, or lung). Radiographic staging was as follows: stage I (hilar adenopathy), three patients; stage II (pulmonary infiltration), 13 patients. ${ }^{11}$ Two groups of criteria were used to determine whether a case of sarcoidosis was "active" for the purposes of this study-firstly, the presence of clinical features such as fever, erythema nodosum, arthralgia, and recent dyspnoea, and secondly a lymphocytic reaction in the alveolar fluid. Eleven patients had active sarcoidosis and five were classified as inactive. Six patients with active sarcoidosis were taking corticosteroids.

Standard laboratory tests were used to measure the following parameters: ACE in bronchoalveolar washings, serum ACE and lymphocyte and macrophage counts in lavaged fluid. ${ }^{12}$ Bronchoalveolar lavage was performed during fibreoptic bronchoscopy after catheterisation of the apical segment of the right lower lobe. Physiological serum $(200 \mathrm{ml})$ were injected and 50 to $75 \%$ of this volume was reaspirated. The supernatant fraction was collected immediately after centrifugation, concentrated 50 times and kept at $-20^{\circ} \mathrm{C}$. Cell viability was assessed by means of Trypan blue, giving an average $75 \%$ live cells. Alveolar ACE and serum ACE were as- 
Table 1 Average levels of alveolar ACE and serum $A C E$ in healthy control subjects, patients with inactive sarcoidosis, and patients with active sarcoidosis. Results are expressed in $[\mathrm{n}] \mathrm{mol} / \mathrm{ml} \mathrm{BAL}$ or $\mathrm{ml}$ serum/min ( \pm standard error)

\begin{tabular}{llcccc}
\hline & ACE & Control & $\begin{array}{l}\text { Inactive } \\
\text { sarcoidosis }\end{array}$ & $\begin{array}{l}\text { Active } \\
\text { sarcoidosis }\end{array}$ \\
\hline Serum & ACE & $48.24 \pm 10.4$ & $67.35 \pm 11.02$ & $79.74 \pm 28$ \\
Alveolar & ACE & $0.134 \pm 0.03$ & $0.3 \pm 0.05$ & $1.28 \pm 0.9$ \\
\hline
\end{tabular}

sayed by the spectrofluorimetric method of Friedland and Silverstein using Hippuryl L, Histidyl $\mathrm{L}$, and Leucine as artificial substrate. ${ }^{13}$

\section{Results}

For control subjects (table 1 ) the average values were as follows: alveolar ACE: $0.134 \pm 0.03[\mathrm{n}] \mathrm{mol} / \mathrm{ml}$ BAL $/ \mathrm{min}$; serum ACE: $48.24 \pm 10.4$ [n] $\mathrm{mol} / \mathrm{ml}$ serum $/ \mathrm{min}$. These results for serum ACE correspond with those of Silverstein. ${ }^{13}$

In patients with sarcoid the overall results are presented in table 2 and active and inactive sarcoidosis are considered separately. In 11 patients with active sarcoidosis, alveolar ACE was abnormally high in all cases and serum ACE was elevated in nine cases. In case 6 alveolar ACE was normal. This patient recovered spontaneously over the next six months with radiographic clearing, suggesting that the $\mathrm{ACE}$ level returned to normal before the other measured parameters. In case 7 the absence of raised serum ACE was a false negative result, since the patient's condition became chronic, its continued activity correlating with sustained high levels of lymphocytes and alveolar ACE. It is possible that corticosteroid treatment was responsible for the normal serum ACE level in this patient. With this one exception in the group with active sarcoidosis, there were no other significant differences between those under corticosteroid treatment (six cases) and untreated patients (five cases). In accordance with Leguern, ${ }^{4}$ we found no correlation between the extent of radiographic shadowing and serum $\mathrm{ACE}$ levels, and the same was true for alveolar ACE.

In the five patients with inactive sarcoidosis lymphocyte levels were lower than $15 \%$ of total cell count. In four of these cases the level of alveolar ACE was low and the patients recovered with or without treatment. The fifth case (16) had a high alveolar ACE level and the patient had a relapse. Once again there were differences between alveolar and serum ACE levels, probably indicating a difference in the evolution of the levels of these enzymes (cases 12, 15).

\section{Discussion}

Serum ACE is considered today as a useful biological marker in sarcoidosis in both diagnosis and management of the disease. Nevertheless the proportion of sarcoidosis patients with a high level of this enzyme in the blood varies from less than $50 \%{ }^{2} 3$ to as high as $70 \%, 1414$ irrespective of whether the method of assay was spectrofluorimetric or radiochemical. There are even greater differences between published results with respect to correlation between serum ACE levels and degree of activity of the disease. Thus Leguern ${ }^{4}$ found no correlation whereas

Table 2 Results of alveolar and serum ACE levels and the percentage of lymphocytes in bronchoalveolar lavage in 16 patients with sarcoidosis. Eleven had active sarcoidosis and five were in a stable condition. Activity was judged either by clinical criteria or by the level of lymphocytes in alveolar washings. The radiographic stage is listed according to the international classification in three degrees of severity (L : hilar lymphadenopathy, $M$ : miliary shadowing). Units as for table 1

\begin{tabular}{|c|c|c|c|c|c|c|c|c|}
\hline \multirow{2}{*}{$\begin{array}{l}\text { Patient } \\
\text { number }\end{array}$} & \multirow{2}{*}{$\begin{array}{l}\text { Radiological } \\
\text { stage }\end{array}$} & \multirow[t]{2}{*}{ Activity } & \multicolumn{2}{|c|}{ Criteria of activity } & \multirow[t]{2}{*}{ Treatment } & \multirow[t]{2}{*}{ Serum $A C E$} & \multirow[t]{2}{*}{ Alveolar $A C E$} & \multirow{2}{*}{$\begin{array}{l}\text { Clinical } \\
\text { outcome }\end{array}$} \\
\hline & & & Clinical signs & $B A L(\%)$ & & & & \\
\hline 1 & II $\mathbf{L}+\mathbf{M}$ & + & + & 43 & 0 & $77 \cdot 19$ & $1 \cdot 1$ & Recovery \\
\hline 2 & II $\mathbf{L}+\mathbf{M}$ & + & + & 45 & Corticosteroids & $73 \cdot 2$ & $1 \cdot 1$ & Recovery \\
\hline 3 & II $\mathbf{L}+\mathbf{M}$ & + & + & 49 & 0 & $107 \cdot 24$ & $2 \cdot 0$ & Chronicity \\
\hline 4 & II $\mathrm{M}$ & + & 0 & 43 & 0 & $134 \cdot 02$ & 1.85 & Recovery \\
\hline 5 & II $\mathbf{L}+\mathbf{M}$ & + & 0 & 45 & 0 & 80.4 & 0.62 & Recovery \\
\hline 6 & II $\mathrm{M}$ & + & + & 27 & 0 & $24 \cdot 72$ & 0.58 & Recovery \\
\hline 7 & II $\mathrm{M}$ & + & + & 50 & Corticosteroids & $39 \cdot 31$ & 0.64 & Recovery \\
\hline 8 & I & + & 0 & 40 & Corticosteroids & 84.98 & 0.59 & Recovery \\
\hline 9 & I & + & + & 54 & Corticosteroids & $79 \cdot 56$ & $1 \cdot 27$ & Recovery \\
\hline 10 & II $\mathbf{M}+\mathbf{L}$ & + & + & 18 & Corticosteroids & $96 \cdot 19$ & 0.59 & Recovery \\
\hline 11 & II & + & + & 54 & Corticosteroids & $80 \cdot 41$ & $3 \cdot 80$ & Chronicity \\
\hline 12 & II $\mathbf{L}+\mathbf{M}$ & - & 0 & 9 & 0 & $76 \cdot 84$ & $0 \cdot 161$ & Recovery \\
\hline 13 & II M & - & 0 & 13 & Corticosteroids & 56.9 & $0 \cdot 12$ & Recovery \\
\hline 14 & II $\mathbf{M}$ & - & 0 & 10 & 0 & $53 \cdot 3$ & $0 \cdot 21$ & Recovery \\
\hline 15 & II $\mathbf{M}$ & - & 0 & 4 & 0 & 81.94 & $0 \cdot 10$ & Recovery \\
\hline 16 & I & - & 0 & 10 & 0 & $67 \cdot 81$ & 0.95 & Relapse \\
\hline
\end{tabular}


Rohrbach ${ }^{1}$ on the contrary found increasingly high levels according to radiographic staging. The disparity between these results may be linked with the variable nature of immune response observed in the course of this disease and it therefore seemed to us more promising to investigate the immune response in the alveoli as analysis of ACE in the peripheral blood might be less pertinent in pulmonary sarcoidosis.

Alveolar macrophages are activated in sarcoidosis and one of the possible consequences of this activation is hypersecretion of angiotensin converting enzyme. The present study measured this enzyme in bronchoalveolar lavage fluid using a well-tried technique. As with serum ACE assay, ${ }^{5}$ until more is known about the levels of alveolar ACE in other respiratory diseases, it is impossible to draw conclusions about the diagnostic specificity of this test.

With regard to assessing disease activity, the clinical criteria for judging activity of pulmonary sarcoidosis are not very reliable, and in the absence of other clinical features, it is impossible to assess the activity of the disease simply on the basis of the chest radiograph in order to decide on the appropriate treatment, although a definite worsening of the chest radiograph may be taken as a criterion of activity. The present series of patients reflects these difficulties of interpretation for of the 11 cases of active sarcoidosis three showed no clinical signs. It is notable however that alveolar ACE was found to be abnormally high in all cases of sarcoidosis judged to be active on the basis of high lymphocyte levels in alveolar lavage fluid whereas serum ACE was found to be misleading in two cases. It is possible that alveolar ACE assay gives a better idea of pulmonary activity in sarcoidosis than does serum ACE. The objection that corticosteriod therapy is responsible for hypersecretion could be advanced, ${ }^{5}$ but among the cases of active sarcoidosis in the present series, alveolar ACE levels were abnormal both for patients under treatment and for untreated patients.

Regarding the prognosis of pulmonary sarcoidosis, although lymphocytosis in alveolar washings may appear to be a criterion of disease activity on a par with clinical signs, this biological finding gives no information about the evolution of the disease, there being no correlation between lymphocyte levels and the intensity of the disease, and furthermore normal levels may be observed temporarily in forms which subsequently relapse. It is possible that bronchial ACE levels, reflecting macrophage activation, may be a better indicator of the likelihood of sarcoidosis to progress or relapse.

Further immunological cell studies, especially into $T$ lymphocyte sub-populations, may distinguish between present activity and the likely outcome of the disease. We consider that this distinction is of $\frac{0}{2}$ therapeutic interest because although active but apparently non-progressive forms appear to respond well to corticosteroids, this treatment is often disappointing in chronic or relapsing disease and there is a temptation to prescribe more immunosuppressive treatment such as azathioprine although the evidence that this treatment improves the prognosis is incomplete.

In conclusion, we believe that assay of alveolar ACE is a complementary biological test which can provide information about the clinical course of sarcoidosis, especially with regard to its pulmonary manifestations. Further assays of this kind, in addition to the study of serum ACE, lymphocyte counts and lymphocyte sub-population counts will probably make it possible to predict the outcome of the disease until such time as its aetiology is discovered.

\section{References}

${ }^{1}$ Rohrbach MS, Deremee RA. Serum angiotensin converting enzyme activity in sarcoidosis as measured by a simple radiochemical assay. Am Rev Respir Dis 1979; 119:761-7.

${ }^{2}$ Silverstein E, Friedland J, Lyons HA, Gourin A. Elevation of angiotensin converting enzyme in granulomatous lymphnodes and serum in sarcoidosis. Ann NY Acad Sci 1976;278:498-513.

${ }^{3}$ Fanburg BL, Schoenberger MO, Bachus B, Snider GL. Elevated serum angiotensin I converting enzyme in sarcoidosis. Am Rev Respir Dis 1976;114:523-8.

${ }^{4}$ Stanislas-Leguern G, Marsac J, Arnoux A, Lecossier D. Serum angiotensin-converting enzyme and bronchoalveolar lavage in sarcoidosis. Lancet 1979;1:723.

${ }^{5}$ Gee JB, Bodel P, Zorn S, Hinman LM, Stevens CA, Matthay RA. Sarcoidosis and mononuclear phagocytes. Lung 1978;155:243-53.

${ }^{6}$ Williams WJ, Davies BH Eighth International Conference on Sarcoidosis and other granulomatous diseases. Cardiff: Alpha Omega Publications, 1980.

${ }^{7}$ Gupta RG, Catchatourian R, Sicilian L, Szidon JP. Angiotensin converting enzyme (ACE) in bronchoalveolar lavage (BAL) in sarcoidosis. Am Rev Respir Dis 1979;119:No 4 suppl, 69.

${ }^{8}$ Lanzillo JJ, Fanburg B. Angiotensin converting enzyme in bronchoalveolar lining fluid. Lancet 1979;1:1200-1.

9 Perrin-Fayolle M, Harf R, Chevalier JP, Biot N, Frobert Y, Kofman J. Intérét des LBA itératifs dans la surveillance des sarcoïdoses. INSERM 1979;84:321-8.

${ }^{10}$ Hunningake GW, Fulmer JD, Young RCJR, Gadek JE, Crystal RG. Localization of the immune response in sarcoïdosis. Am Rev Respir Dis 1979;120:49-57.

11 Turiaf J. Diagnostic de la sarcoïdose. Rev du Pract 1974; 24:4209-13.

12 Perrin-Fayolle M, Harf R. Le lavage bronchoalvéolaire. Une technique d'avenir. Lyom Médical 1978;239:339-40.

${ }^{13}$ Friedland J, Silverstein E. A sensitive fluorimetric assay for serum angiotensin-converting enzyme. Am J Clin Pathol 1976;66:416.

${ }^{14}$ Studdy P, Bird R, James DG, Sherlock S. Serum angiotensin converting enzyme in sarcoidosis and other granulomatous disorders. Lancet 1978;2:1331-4. 